\title{
Communication in Authoritarian Parenting on Learner Participation in Early Childhood Education Science Class in Homabay County, Kenya
}

\author{
Odundo Paul Amollo ${ }^{1} \&$ Ganira Khavugwi Lilian ${ }^{1}$ \\ ${ }^{1}$ Department of Educational Communication and Technology, University of Nairobi, Nairobi, Kenya \\ Correspondence: Odundo Paul Amollo, Department of Educational Communication and Technology, University \\ of Nairobi, P. O. Box 79162- 00400 Nairobi, Kenya.
}

Received: September 26, 2018

Accepted: November 22, $2018 \quad$ Online Published: December 11, 2018

doi:10.20849/jed.v2i3.520

URL: https://doi.org/10.20849/jed.v2i3.520

\begin{abstract}
Communication is the process of reaching mutual understanding where participants not only exchange information, ideas and feelings but also create and share meaning. Effective communication imparts knowledge and paves way towards building and strengthening relationships which uphold peace between parents and children for lasting associations. However, the authoritarian parenting style tends to manipulate communication which creates fear and compromise learner participation in class. The study explored the relationship between communication in authoritarian parenting model and participation of learners in Early Childhood Education (ECE) science classroom in Homabay County, Kenya. The population of the study involved 314 respondents including 4 County education officers; 60 head teachers; 60 ECE teachers attached to public primary schools; 120 learners and 70 parents. The teachers' questionnaire was used as the main data collection tool. Correlation analyses were performed to determine which demographic characteristics should be used as control variables. Regression analyses were also performed to examine the relationship between communication in authoritarian parenting model and children's participation in class activities. Data was gathered, summarized and analyzed by reading the information collected through the research instruments and pattern trends and relationships from the information gathered were established. Descriptive statistics were used to analyze qualitative data while quantitative statistics were employed to match authoritarian parenting numbers to learner participation attributes. Frequency distribution tables were used to present the data. Anchored on social learning theory, the study findings supported the view that communication in authoritarian parenting model is negatively related to children's participation in class. The $91 \%$ of ECE teachers confirmed that learners from authoritarian settings could not express themselves well as a result of limited communication existing between the child and the parent and only 9\% observed eloquence in the learners of authoritarian parents. For further research the study suggested that since authoritarian mothers and fathers behave differently, studies should be done separately to assess consistency of the parenting model in both parents.
\end{abstract}

Keywords: authoritarian parenting model, parent - child communication, class motivation, science class, learner participation

\section{Introduction}

The Convention on the rights of children CRC (1998) acknowledges communication as a constitutional right for expressing needs and opinions vital in achieving goals for social development. As a constitutional right, the CRC (1998) emphasizes that through communication, a child should be heard, access information, maintain privacy, develop cultural identity and appreciate own heritage and beliefs. In this regard, the responsibility of raising children is vested in the family as stipulated under the United Nations Convention on the rights of the Children (UNCRC, 1989). Further, UNCRC (1989) recognized that children have human rights and need special care and protection by adults especially parents for effective growth and development. Based on this realization, the CRC (1989) emphasized that children be raised in an atmosphere of love, happiness and understanding for harmonious development of individual personality which is attainable through appropriate parenting models. This is in tandem with Elizabeth, Gregory, Fosco and Thomas (2010) affirmation that the family is a child's "social network" which offers an immediate environment during formative years that contributes to behavior modification and sustainable development. In support of this position, Samiullah (2016) affirmed that authoritarian parenting style model influences a child's development in line with set standards of conducts which 
determine nature of communication patterns.

According to Canary (2011) communication is anchored on interaction between individuals for common understanding and exchange of information, ideas and feelings for achieving social skills. Further, effective communication imparts knowledge and paves way towards strengthening attachment and upholding peace for nurturing relationship between parents and children. In support of these sentiments, Knight and Holt (2014) asserted that healthy and appropriate communication between parents and child results in enhanced academic achievements and less behavioral challenges for developing trust, confidence and positive relations. This is in concurrence with Toombs, Unruh and McGrath (2018) suggestion that positive parenting requires effective communication for developing interpersonal skills and secure attachments that can be passed on to future generations. In instances where appropriate communication is reinforced, tolerance, independence, and personal development is nurtured which in turn assist learners in enhanced participation in class activities. On the other hand, ineffective communication denies children space to freely interact and express own needs therefore weakening participation and disrespect for others.

While parents should be talking to children and consulting, Samiullah (2016) affirmed that restricted communication in authoritarianism parenting style reduces language and communication skills. Inappropriate communication skills are likely to lower self-esteem, confidence and competence among learners therefore creating a barrier to effective participation in class activities. In a study on parenting style and involvement of parents in school activities, Marina, Dragana and Marija (2013) established that children from authoritarian parenthood are less confident and demonstrate difficulty in social interactions due to inadequate freedom in making choices and restricted efforts in communication. As a result, children from authoritarian parents are less resourceful, socially-adept and more likely to be involved in bullying activities which weaken effective participation in school. This supports an earlier argument by Baumrind (1991) that parents make claims on children to become integrated into the whole family by maturity demands, supervision, disciplinary efforts and willingness to confront the child who disobeys. Such parents tend to utilize punishments rather than discipline and are not willing to explain reasons in relation to set rules. More still, Pinquart (2017) established that authoritarian parents control and evaluate behavior and attitudes of children in accordance with a set standard of conduct motivated and formulated by a higher authority as a way of good parenting. Based on this assertion, the parenting model of a parent should influence child's relationship with others and nurture development of personal strength for effective learner participation in class.

Learner participation is connected to conversation which naturally involves extensive dialogue with the entire class influenced by learner-led communication. As noted by Blazar and Matthew (2017) participation is an effective feature of many course designs that results in insightful comments and interesting connections by learners which foster a high level of energy and enthusiasm for learning. In addition, Peter (2017) in a study on innovation in education indicated that active participation require environments that support free communication where learners can take risks, make errors and be exposed to diverse ways of thinking as part of the learning. Therefore, reinforcing participation through positive environments allows learners to acknowledge contribution to a shared experience which builds sense of collectivism that nurture communication skills. However, Dawood (2015) opined that reluctance in talking openly is an obstacle to a sound relationship since communication is the heart of participation and sharing of experiences in class situation. Further, in a study on parenting styles and academic achievement, Purification and Alicia (2018) opined that inadequate conversation and motivation to communicate openly like in authoritarian parenting weakens opportunities for learning and participation in class. In this regard, learners who experience inadequate motivation are likely to feel discouraged, irritated, baffled and embarrassed which inhibits chances of talking and social interactions. Given that the choice authoritarian parents make influences success in school, Checa and Abundis-Gutierrez (2017) commented that this may not hinder having a determining factor on character, personality and competence of learners. Appropriate task of parenting is the socialization of children which requires parental guidance coupled with effective communication skills that encourage learner participation in class. This is because a socially competent child is independent, responsible, achievement oriented and energetic to effectively participate in class activities. In support of this contention, Pinquart and Kauser (2018) indicated that the role of parents should be considered since interaction between a child and a parent has a significant influence on nature of participation. Based on this back ground, the study examined relationship between communication in authoritarian parenting and learner participation in science activities, focusing on language development, social withdrawal, emotional balance and anti-social behavior.

\subsection{Communication, Language Development and Learner Participation}

Language competence emphasizes that effective communication between parents and children are passionate, eloquent, powerful and emotional for mutual relationships. In instances where parents reinforce communication 
with children, there are high chances of improved learner attitudes towards schooling and development of language skills which encourage participation in class. However, Argyriou, Bakoyannis and Tantaros (2016) affirmed that authoritarian parents are less likely to encourage dynamic verbal interactions which in turn hinder language development of the child due to inadequate exposure and practice at home. Additionally Erin and Shelia (2017) affirmed that due to inadequate communication skills, the child fears and avoids participating in class activities and even asking questions at home. Therefore, early negative parenting beliefs like "children should adhere to adult directives without question and expectations of total child obedience" negatively impacts on children's language development and subsequently on early academic achievement which inhibits both participation during science activities and learning process. This is in agreement with Yi-Chan and Mei-Ju (2013) affirmation that children with speech, language and communication difficulties especially from authoritarian homes are significantly disadvantaged in ability to access the national curriculum. Such children are likely to avoid participating in class since every educational skill presupposes use of language. In this regard, parents should encourage free communication with children to enable language development which is critical in enhancing learner's participation during science activities.

\subsection{Communication, Social Withdrawal and Learner Participation}

Social withdrawal exposes learners to a state of absolute or near-complete insufficient contact with individuals in society which influences communication skills. For healthy attachment, a child requires warmth and affection expressed by parents for reinforcing life-long positive learning outcome. In supporting this affirmation Ganira, Odundo, Ngaruiya, Obae (2015) confirmed that parents who demonstrate warmth and affection have children with high self-esteem, improved academic achievement, enhanced communication, and few psychological challenges. This requires parents to create a strong bond immediately starting from infancy through positive interaction for the child to develop physically, socially and emotionally. Further, Monica, Calogero, Giuseppe, Ivan and Simona (2017) emphasized the role of early interpersonal experiences in development of cognitive skills when parents bond with the child from infancy. Monica et al (2017) study indicated that mothers' parenting style characterized by lower level of nurturance is predictive of the disconnection and rejection domain between learning and participation in school. In this regard, parents should be reminded from time to time to talk, listen and respond to child's needs and gauge on how to enrich the environment in order to support effective participation. This is based on the assertion of Pellarone, Craparo and Tornanuoni (2016) that authoritarianism parenting model can lead to greater social withdrawal especially in children with low cognitive skills. The socially withdrawn child will appear quiet in all social settings including class hence avoid participating.

In a study on relationships between perceptions of parental punitive discipline, Kariuki, Akola and Ciriaka (2015) argued that use of disciplinary and forceful measures to enforce proper behavior triggers anger, resentment and deceit which weaken healthy parent child relationship. In concurrence, Anne-Lise (2016) indicated that preschool children with authoritarian parents are withdrawn and unhappy, appear anxious and insecure with peers and react bitterly when frustrated. Hence teachers have to interact effectively and provide appropriate class climate where learners from authoritarian parents can develop self-esteem and confidence for participating in class activities. In support of this position, Yi-Chan and Mei-Ju (2013) noted that since children of authoritarian parents are withdrawn and less likely to internalize and accept own standards of society's acceptable behavior, teachers should model behavior that can be emulated by all learners. Drawing from Yi-Chan and Mei-Ju (2013) assertion, Ganira, Odundo and Mwanda (2015) suggested that though authoritarian parents limit opportunities for verbal and emotional attachments, this can be enhanced if teachers increase learner's sense of autonomy, competence, relatedness and persistently acknowledge any contribution made in class. This is based on realization that authoritarian parents demand certain behavior without explaining why and often not listening or providing adequate emotional support for encouraging learner participation in class.

\subsection{Communication, Anti-social Behavior and Leaner Participation}

Anti-social behavior which is culturally unacceptable among children is manifested through defiance, hostility, aggression and rebellious actions that violate norms and shared values. This is in agreement with Camilla, Maria and Anders (2016) affirmation that children with behavioral challenges rarely complete schooling, experience inadequate competency with skills, poor relationships with peers and lower involvement in extracurricular activities. For children experiencing behavioral problems, school may be the only secure place of protection and teachers should strengthen and stimulate free self-activities, creativity, social participation and motor verbal communication for effective learning to take place. Through such efforts children are likely to trust one another, interact successfully, demonstrate independence, be willing to try new activities and express needs through effective communication. In support of this argument, Ganira, Odundo, Ngaruiya, and Obae (2015) affirmed that with effective communication, learners pay attention to social cues, maintain friendly interaction, perceive and 
appreciate others' viewpoints which in turn lead to social responsibility. This is based on the premise that children's communication, social development, cognitive skills and approach to learning are prerequisites for effective learner participation in class activities.

However, according to Thoma, Norra, Juckel, Suchan and Bellebaum (2015) parental attributes such as neglect, strictness, control, punishment, and inadequate support generate child behavioral problems that impair learning achievement. Children with behavioral challenges could easily exhibit poor social skills, lower self-esteem and higher levels of depression which weaken participation in class. Further, in a study on the association between children's behavior and parenting of care givers, Kota, Yosuke and Masumi (2016) found out that, parents influence children's behavior (punitive and strict) which heighten to antisocial behavior that lower learner participation. In supporting this assertion, Samiullah (2016) indicated that family environments constitute the basic ecology where children's behavior is learned, encouraged or suppressed. In instances where children's behavior is reinforced positively, there are lower risks of developing social isolation. On the other hand, when behavior is suppressed there are high chances of peer aggression, conduct problems, hostility which influence learner participation. As noted by Monica et al (2017) in a study on influence of parenting on maladaptive cognitive schema, children internalize standards for behavior; psychological and emotional modulating through exposure to harsh interactions with parents, such as yelling, arguing and slapping. In this way, punitive negative discipline by parents leads to cognitive and emotional maladjustment in children resulting in display of anger and defiance which in turn influence participation in class due to unruly behavior.

\subsection{Communication, Emotional Balance and Learner Participation in Science Class}

According to Mark and Xuemei Huang (2015) emotional balance is the ability of the mind and body to sustain stability, flexibility and challenges even during stressful situations. Further, emotional balance promotes physical health and self-awareness which nurtures personal wellbeing and growth. This is in tandem with Carlos, Valiente, Jodi and Eisengerg (2012) affirmation in a study on linking student's emotions and academic achievement indication that emotional balance promotes positive, successful and intellectual functioning of the mind through broadening of one's cognitive awareness and realization of possible resolutions to challenges. In addition, in a study on social and emotional learning Schonert-Reich and Kimberly (2017) opined that stability nurtures competencies through stimulating the mindset, skills, attitudes and sense of belonging which enable learners to actively get involved in class activities. To achieve this, teachers should avoid mocking learners, but initiate child-friendly learning environment to accommodate children from authoritarian settings by rewarding positive behavior, having clear expectations and guidelines for appropriate consequences.

Without appropriate guidance and with anger that develops as a result of neglect, Ganira, Odundo, Kahiga, Muriithi, Mwangi and Koring'ura. (2016) noted that children with emotional discrepancy often act out of emotions in ways that lead to problems with school or with the law. Such children may end up prime candidates for gang involvement due to desire for some semblance of family. Gangs although unhealthy for children, provide sense of connectedness and the warmth desired for surviving in society, (Carlos, et al (2012). Based on this position, Ganira, Odundo and Ngaruiya (2015) pointed out that failure of parents to nurture warm and supportive relationships with the child weakens development of emotional understanding and empathy. In an effort to address this concern, parents should intentionally foster individuality, self-regulation and self-assertion by being attuned, supportive and acquiescent to children's needs and emotional stability. This would assist children in developing self-awareness, independence, decision making and competence skills for effective participation in class. It is based on this background that the study sought to determine relationship between communication in authoritarian parenting model and participation of learners in Early Childhood Education Science classroom in Homabay County, Kenya.

\section{Statement of the Problem}

Authoritarian parenting is manifested in limited communication, low parental availability, unquestionable obedience and high control which weaken relationships between parents and children. Weak attachments between parents and children from authoritarian backgrounds results in low confidence and difficulty in social interactions due to inadequate freedom in making choices and restricted efforts in communication. Since parents with authoritarian style have high expectations of children yet provide little nurturance, educators are faced with tasks of promoting different types of learners who acquire knowledge in unique and individual ways. This is based on the premise that children from authoritarian settings show persistence in the face of failure whereas others give up or chooses to work on less challenging tasks. The study was based on the premise that participation in science lesson in preschools has been ineffective or not convincing. This is in spite of the fact that the government highlights goals of education from preschool tier to higher learning institutions on 
achievement and participation of learners. Children with inadequate motivation to engage in challenging tasks demonstrate signs of withdrawal and fear of failure resulting in punishment by authoritarian parents who believe that outcomes are independent of one's actions. Demonstration of fear tend to attribute failure to inadequate ability rather than insufficient effort making the child view discontent as internal, stable and relatively unchangeable that only results in punishment. Such children develop poor social skills, low esteem and are at risk of negative effects as well as expectations which result to low class participation. Inadequate class participation leads to avoidance of challenging tasks and inaccurately underestimates ability based on past reactions of parents' belief that future tasks are unsuccessful due to inability. In instances where appropriate guidance is provided through supportive learning environments, children reared in authoritarian settings may be relatively well-behaved which in turn results to improved communication, enhanced social skills, resourcefulness and increased autonomy for effective participation in class activities. Based on this realization, the study explored communication in authoritarian parenting model and participation of learners in Early Childhood Education Science classroom.

\section{Purpose and Objectives}

The purpose of this study is to examine the relationship between communication in authoritarian parenting and learner participation in science class. The objective was to determine extent to which language development, social withdrawal, anti-social behavior and emotional balance influence learner participation in science class.

\section{Methodology}

This study was anchored on descriptive survey design Kothari and Grag (2014) to collect and analyze data to determine the relationship between authoritarian parenting model and learner participation in class. According to Kothari and Grag (2014) descriptive survey design describes the characteristics of the population under study without focusing on why certain phenomenon occurs. Purposive sampling was used to select 60 head teachers, 60 ECE teachers, 4 area education officers and 120 learners while snowballing technique was used to recruit 70 parents who participated in this study. The study used interview schedules for parents and questionnaires to collect data from preschool teachers. This is in accordance with the assertion of Orodho, Nzabalirwa, Odundo, Ndirangu and Ndayambaje, (2016) that a questionnaire has the ability to collect a large amount of information in a reasonably quick space of time. Further, the study used interview schedules to gather in-depth information on the parenting style from parents which gave them time to think about responses. Prior to the study, the head teachers of the participating ECE centers were visited and informed of the purpose of the research and how it would be conducted. We also contacted the teachers who agreed to participate and have learners partake of the stud and explained how much time was required and the assistance they would need to provide. The participating teachers were requested to distribute and collect parental consent forms which included permission to voice record each participant. Data obtained from the field in raw form was analyzed to give meaning using frequencies and measures of central tendency. With the aid of Microsoft excel, data was analyzed and findings presented using tables.

\section{Theoretical Framework}

This study was anchored on Lev Vygotsky's (2005) social interaction theory. According to Vygotsky (2005), social interaction precedes development, consciousness and cognition as the end product of socialization and societal behavior. This implies that children learn in social context from each other assisted by teachers through development of appropriate learning environments and supportive family settings. Supportive family backgrounds nurture effective communication which imparts knowledge and paves way towards strengthening strong attachment between parents and children. For effective participation to be realized, a child needs appropriate social ties in an interactive environment that supports communication skills. While children of authoritarian parents show high levels of obedience, studies have shown that this parenting model also produce negative outcome in children's development such as fear of failure coupled with low social response, Pinquar (2017) and poor adjustment at school (Schonert-Reich \& Kimberly, 2017). In this regard, Vygotsky (2005) indicated that the potential for cognitive development is anchored on zone of proximal development that requires scaffolding from parents and care givers. With appropriate guidance from parents and collaboration with peers, learners are likely to develop independent problem solving skills potential encouraging effective communication. Further effective social interactions coupled with appropriate parenting styles encourage communication, language development, emotional balance and discourage anti-social behavior that hinder participation. All these supports are likely to promote enhanced learner participation in science activities which this study sought to examine. 


\section{Conceptual Framework}

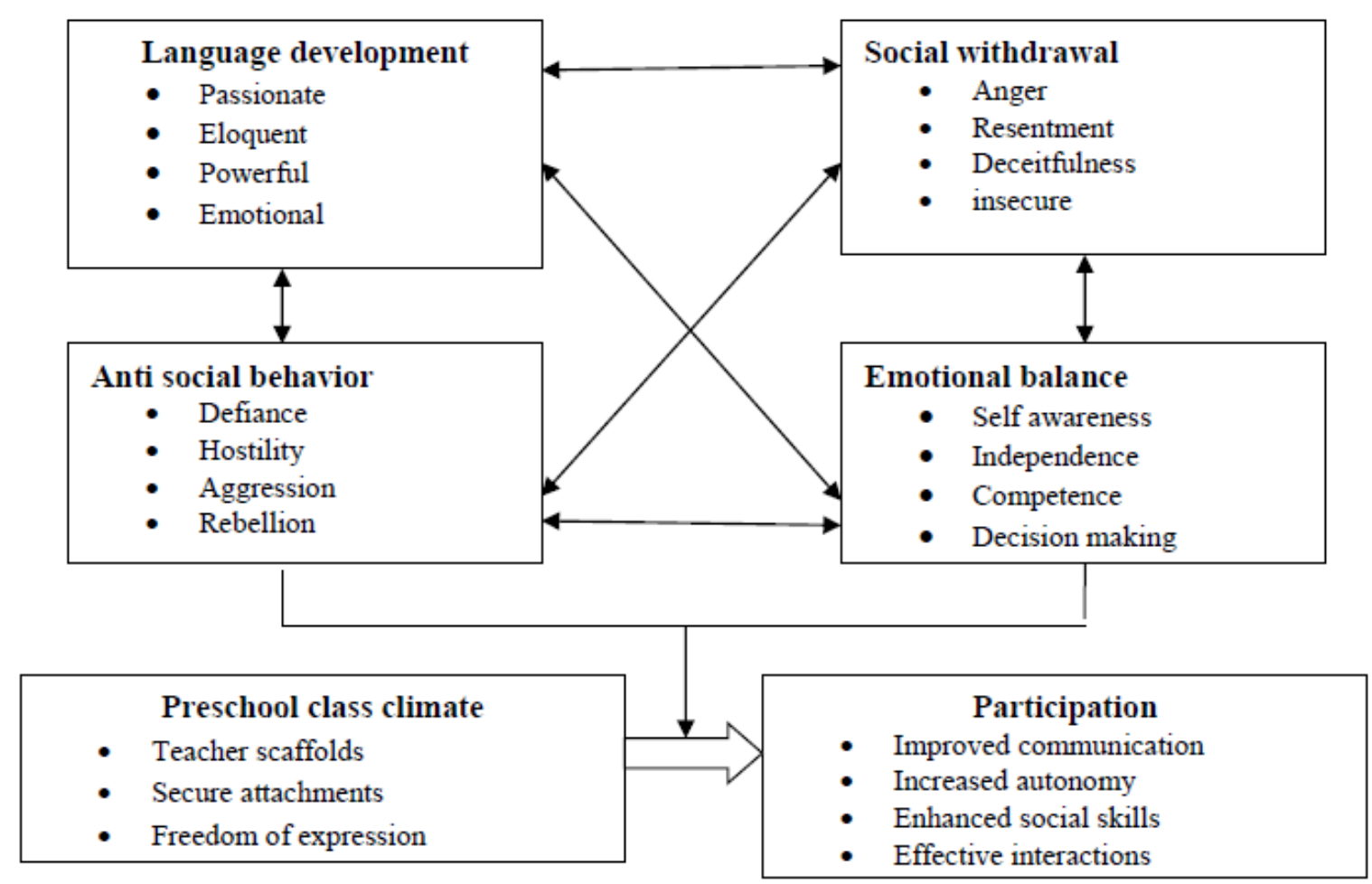

Figure 1. Conceptual framework on relationship between communication in authoritarian parenting and learner participation

According to the conceptual framework, effective communication is anchored on learner passion, eloquence, power and emotional ability. Social withdrawal manifests itself in anger, resentment, deceit and unsecure attachments emanating from authoritarian parenting style. Since learners from authoritarian parents have limited social ties they tend to demonstrate anti-social behavior in form of defiance, hostility towards authority, aggression and rebellion which limit participation in class. In instances where children are supported by adults they develop self-awareness, independence, competence and decision making skills which are prerequisites for effective communication. Further, when preschool teachers offer scaffolds, secure attachments, freedom of expression and assurance, there are high chances of effective learner participation through improved communication, increased autonomy, enhanced social skills and interactions.

\section{Study Findings and Discussions}

The study sought to examine the relationship between communication in authoritarian parenting and learner participation in early childhood education science class in Homabay County. Findings are illustrated in Table 1, 2, 3, 4 and 5 .

\subsection{Expressiveness and Participation of Learners}

Erin and Shelia (2017) posited that children who freely talk to parents tend to participate more in class activities. On the same vein, Vygotsky (2005) indicated that children in every culture master the complicated system of the native language learnt from the family members who are critical to cognitive development and learning unless severe deprivation or physical problems interfere. The study determined expressiveness and participation of learners in science class. The study results are shown in Table 1. 
Table 1. Expressiveness and learner participation

\begin{tabular}{llrlr}
\hline EXPRESSIVENESS & ECE TEACHERS & & HEADTEACHERS & \\
\hline & F & $\%$ & F & $\%$ \\
Passionate & 6 & 10 & 7 & 14 \\
Eloquent & 9 & 15 & 12 & 24 \\
Powerful & 5 & 8.33 & 6 & 12 \\
Emotional & 40 & 66.67 & 25 & 50 \\
TOTAL & $\mathbf{6 0}$ & $\mathbf{1 0 0}$ & $\mathbf{5 0}$ & $\mathbf{1 0 0}$ \\
\hline
\end{tabular}

Study findings in Table 1 shows that out of 60 ECE teachers used in this study, $6(10 \%)$ confirmed that children of authoritarian parents were passionate during class activities especially in science. In addition, 7 (14\%) out of the 50 head teachers confirmed that children were passionate and freely interacted with peers in class. This is a deviation from Argyriou, Bakoyannis and Tantaros (2016) argument that children of authoritarian parents are quick tempered and easily moved to anger. Further findings show that $9(15 \%)$ of the ECE teachers observed that the learners were eloquent, this was also confirmed by $12(24 \%)$ of the head teachers. This lower percentage of eloquence is in line with Erin and Shelia (2017) assertion that the development of speaking skills requires fuller and more intensive attention to make sure that children acquire appropriate stock of words. On the other hand, majority of ECE teachers, 40(66.67\%) observed that the learners were emotional due to strictness from authoritarian parents. This confirms with the findings of Yi-Chan and Mei-Ju (2013) that authoritarian children are quick tempered hence emotional which influence participation. The question of expressiveness when posed to one respondent-teacher during a discussion yielded several interesting results as captured below:

Parents should be available and easy to talk to, listen to children's needs, view points and contributions. The parents should minimize name calling, criticism, threatening, blaming or minimizing feelings of children. The goal of communicating openly is not just for children to follow directives but also assist in learning how to express themselves. Effective parent-child communication allows children to develop self-esteem and confidence which nurture relationships for enhancing sense of safety, acceptance, inclusion and respect at home.

\subsection{Social Withdrawal and Learner Participation}

Socially withdrawn children may feel misunderstood, irritable and exhibit lower self-esteem which weakens healthy attachment with parents. Without healthy attachments, children from authoritarian settings begin to feel lonely, isolated and discouraged to actively participate in class activities. Based on this premise, teachers were requested to indicate extent to which social withdrawal influences learner participation in science activities. The findings are indicated in Table 2 .

Table 2. Social withdrawal and learner participation

\begin{tabular}{lll}
\hline SOCIALLY WITHDRAWN & TEACHERS & $\%$ \\
\hline & F & 70 \\
YES & 42 & 30 \\
NO & 18 & 100 \\
TOTAL & 60 & \\
\hline
\end{tabular}

Analysis in Table 2 shows that $42(70 \%)$ of the ECE teachers observed that learners from authoritarian homes were socially withdrawn which was attributed to inadequate social relationships and parental care. In concurrence with this finding, Pellarone, Craparo and Tornanuoni (2016) indicated that authoritarianism parenting model can lead to greater social withdrawal especially in children with low cognitive skills. The socially withdrawn child will appear quiet in all social settings including class hence avoid participating. However in a departure from this assertion, one teacher had this to say on social withdrawal

"A blend of authoritarian parenting model with permissive parenting style tends to have a more inclusive child who participates in and out of school realizing higher learner achievement. This is 
because these children from authoritarian families tend to be withdrawn in and out of classroom keeping off all the social activities in the presence of peers thus even avoiding participation in class activities".

Additional analysis revealed that $18(30 \%)$ of the teachers observed that learners from authoritarian families were not socially withdrawn when in and out of class given that they were able to fit in the harsh home environment or just tried to make good use of the stress free opportunities in school. This corroborates with the affirmation of Ganira, Odundo and Mwanda (2015) that though authoritarian parents limit opportunities for verbal and emotional attachments, communication can be enhanced when teachers increase learner's sense of autonomy, competence, relatedness and persistently acknowledges any contribution they make in class.

\subsection{Learners Antisocial Behavior and Participation in Class Activities}

Parenting model that exists in a home greatly influences child's behavior. In homes where authoritarian parenting is practiced, children tend to behave unreasonably compared to those in non-authoritarian homes. This is supported by Thoma et al (2015) affirmation that authoritarian parenting model contributes to antisocial behavior by raising children temperament and could actually be more harmful to children with high behavioral impulse control. Social learning theory suggests that a child learns behavior from interacting with significant people in their environment, particularly parents and this behavior are maintained through modeling and reinforcement.

Table 3. Antisocial behavior and learner participation

\begin{tabular}{llrlr}
\hline RESPONSE & TEACHERS & & PARENTS \\
\hline & F & $\%$ & F & $\%$ \\
YES & 44 & 73.3 & 9 & 18 \\
NO & 16 & 26.67 & 41 & 82 \\
TOTAL & $\mathbf{6 0}$ & $\mathbf{1 0 0}$ & $\mathbf{5 0}$ & $\mathbf{1 0 0}$ \\
\hline
\end{tabular}

Findings from Table 3 show that $44(73.33 \%)$ of the teachers felt that antisocial behavior is demonstrated by children through bullying, aggression, and rebellion while 9 (18\%) of the parents had also observed antisocial behaviors among children. This was because the parents unintentionally reinforced undesirable behaviors in attempt to appease children. This is supported by Kota et al (2016) assertion that the coercive nature of parent-child interaction results in an increased risk of difficulties when negative spiral patterns of reinforcement involving both the parent and the child go unchallenged. When the patterns are established in an authoritarian environment, they result in an escalation of negative behavior on the part of the child as well as the child's problematic behavior. However $41(82 \%)$ of the parents as well as $16(26.67 \%)$ of the teachers were in agreement that they did not observe any antisocial behavior in children. This was as a result of parents education background since the majority were primary school leavers and were not passionate in child rearing practices while for the teachers it was as a result of shorter periods of stay in their work stations hence had not studied the learners well.

\subsection{Emotional Balance and Learner Participation}

Emotional balance promotes physical health and self-awareness which nurtures personal wellbeing and growth among children. With developed language skills, children can negotiate roles in play situations, organize activities, clarify thoughts to others and make it clear when they are unhappy with a situation. To ascertain this, parents and teachers were requested to indicate whether learners acted out emotions in and out of class. Findings are shown in Table 4. 
Table 4. Emotional balance and learner participation

\begin{tabular}{llclr}
\hline EMOTIONALLY & TEACHERS & \multicolumn{3}{c}{ PARENTS } \\
\hline BALANCED & F & $\%$ & F & $\%$ \\
Yes & 60 & 100 & 47 & 94 \\
No & - & - & 3 & 6 \\
TOTAL & 60 & 100 & 50 & 100 \\
\hline
\end{tabular}

Out of 60 preschool teachers as shown in Table 4, 60(100\%) confirmed that learners did act out of emotions as a result of developmental stage, inadequate guidance and neglect from authoritarian parents. This is in agreement with Carlos, et al (2012) assertion that children of authoritarian parents are quick tempered and very emotional. On the other hand $47(94 \%)$ of the parents also confirmed that children acted out of emotions, resisted any form of correction and acted without appropriate reasoning. While $3(6 \%)$ of the parents confirmed that children did not act out of emotion was an indication that it was normal for a child to once in a while release emotions as suggested by (Schonert-Reich and Kimberly, 2017).

\section{Conclusions}

The study sought to determine relationship between communication in authoritarian parenting model and participation of learners in Early Childhood Education Science classroom in Homabay County, Kenya. Findings of the study showed that $9 \%$ of the ECE teachers observed eloquence in learners from authoritarian homes. This implied that $91 \%$ of the teachers confirmed that the learners could not express themselves well as a result of limited communication existing in between children and parents. Secondly, on social withdrawal, $70 \%$ of the teachers observed that learners were socially withdrawn and this was attributed to inadequate social relationship between authoritarian parents and the child. Finally as a result of limited communication at home, all ECE teachers $100 \%$ confirmed that children from authoritarian homes were emotionally imbalanced and were quick tempered which influenced participation in science class.

\section{Recommendations}

The recommendations were made based on the study findings

- Teachers should apply knowledge in psychology of learning to sensitize parents through community mobilization on the need of effective social interactions and communication for encouraging learner participation.

- Children should be exposed to a variety of vocabulary from early years of learning which is vital for language development. Variety of vocabulary assists in developing confidence, self-esteem and in turn reinforces participation in class.

- Early intervention with parent-child should concentrate on enhancing parent's sensitivity to children needs in encouraging aspects of family communication. This is likely to reduce behavior challenges and increase self-esteem vital for participation.

- Parents should apply a mixture of three parenting styles; authoritarian, permissive and authoritative to keep balance in children's behavior.

- Further research is needed on authoritarian parenting style and support programmes for strengthening rearing skills that can reinforce child development, improve children's lives and nurture social relationships.

\section{References}

Anne-Lise, S. (2016). Dealing with children with withdrawn behavior. Unpublished Thesis for the Degree of Doctor of Philosophy. Norwegian University of Science and Technology.

Argyriou, E., Bakoyannis, G., \& Tantaros, S. (2016). Parenting Styles and Trait Emotional Intelligence in Adolescence. Scandinvian Journal of Psychology, 57, 42-49. https://doi.org/10.1111/sjop.12266

Baumrind, D. (1991). The influence of parenting style on adolescent competence and Substance use. Journal of Early Adolescence, 11(1), 56-95. https://doi.org/10.1177/0272431691111004

Blazar, D. \& Matthew, A.C. (2017). Teacher and Teaching Effects on Students' Attitudes and Behaviors. Educational Evaluation and policy analysis, 39(1), 146-170. https://doi.org/10.3102/0162373716670260 
Camilla, J., Maria, B., \& Anders, T. (2016). Parent Programs for Reducing Adolescents Antisocial Behavior and Substance Use. Journal of Child and Family Studies, 25, 811-826. https://doi.org/10.1007/s10826-015-0263-y

Canary, H. (2011). Communication and Organizational Knowledge: Contemporary Issues for Theory and Practice. Florence, K.Y: Taylor \& Francis.

Carlos, V., Jodi, S., \& Eisengerg, N. (2012). Linking Student's Emotions and Academic Achievement: When and Why Emotions Matter. Child Development Perspective, 6(2), 129-135. https://doi.org/10.1111/j.1750-8606.2011.00192.x

Checa, P., \& Abundis-Gutierrez, A. (2017). Parenting and Temperament Influence on School Success in 9-13 Year Olds. Frontiers in Psychology, 8, 533. https://doi.org/10.3389/fpsyg.2017.00543

Dawood, A.M. (2015). Motivating Reluctant EFL Students to Talk in Class: Strategies and Tactics. Theory and Practice in Language Studies, 5(8), 1703-1709.

Elizabeth, A.S., Gregory, M., Fosco, \& Thomas, J.D. (2010). Implementing Interventions with Families in Schools to Increase Youth School Engagement: The Family Check-Up Model. School Mental Health, 2(2), 82-92. https://doi.org/10.1007/s12310-009-9025-6

Erin, E.W., \& Shelia, M.K. (2017). Young Children's Risk- Taking: Mothers' Authoritarian Parenting Predicts Risk-Taking by Daughters but Not Sons. Child Development Research.

Ganira, K.L., Odundo, P.A., \& Mwanda, S. (2015). Influence of psychological needs on Participation of children aged 4-6 years with physical disability in Early Childhood Education classes in Starehe Division, Kenya. Journal of Educational Research and Studies, 3(2), 30-40.

Ganira, K.L., Odundo, P.A., \& Ngaruiya, B. (2015). Effects of Emotional Needs on Participation of Children Aged 4-6 with Learning Disability in Early Childhood Centers in Starehe Division, Nairobi County, Kenya. World Journal of Education, 5(3), 79-90.

Ganira, K.L., Odundo, P.A., Kahiga, W.R., Muriithi, M.E., Mwangi, J., \& Koring'ura. J.C. (2016). Teacher Sustenance of Emotional Balance among Children aged 4-6 with Disability in Kenya: Addressing Safety, Actualization and Independence. International Journal of Technology and Inclusive Education (IJTIE), 3(I), 948-955.

Ganira, K.L., Odundo, P.A., Ngaruiya, B., \& Obae, R. (2015). Impact of Social Needs on Participation of Children Aged 4-6 with Disability in Early Childhood Education Classes in Starehe Division in Nairobi County, Kenya. International Journal of Elementary Education, 4(2), 25-34. https://doi.org/10.11648/j.ijeedu.20150402.12

Kariuki, N.S., Akola, P.J.O., \& Ciriaka, G. (2015). Relationship between Perceptions of Parental Punitive Discipline and Involvement in Delinquent Behaviors among Selected Kenyan Secondary School Students. Journal of Educational and Social Research, 5(1), 329.

Knight, C.J., \& Holt. N.L. (2014). Parenting in Youth Sport. Understanding and Enhancing Children's Experiences. Sport Exercise, 15, 155-16. https://doi.org/10.1016/j.psychsport.2013.10.010

Kota, S., Yosuke, K., \& Masumi, I. (2016). The Association between Children's Behavior and Parenting of Caregivers: A Longitudinal Study in Japan. Front Public Health. 4, 17.

Kothari, C.R., \& Grag, G. (2014). Research Methodology Methods and Techniques (3rd ed.) New Delhi: New Age International Publishers.

Marina, M., Dragana, J., \& Marija, J. (2013). Parenting Style, Involvement of Parents in School Activities and Adolescents' Academic Achievement. Procedia Social and Behavioral Sciences, 128, 288-293.

Mark, L.L., \& Xuemei Huang, M.D. (2015). Neural control of movement stability: Lessons from studies of neurological patients. Neuroscience, 301, 39-48. https://doi.org/10.1016/j.neuroscience.2015.05.075

Monica, P., Calogero, I., Giuseppe, M., Ivan, F., \& Simona, M.Z. (2017). The influence of parenting on maladaptive cognitive schema: A cross-sectional research on a group of adults. Journal of Psychology Research and Behavior Management, 10, 47-58. https://doi.org/10.2147/PRBM.S117371

Orodho, J.A., Nzabalirwa, W., Odundo, P.A., Ndirangu, P.W., \& Ndayambaje, I. (2016). Quantitative and Qualitative Research Methods in Education and Social Sciences. Kanezja Publishers \& Enterprises Nairobi, Kenya. 
Pellarone, M., Craparo., \& Tornanuoni, Y. (2016). Relationship between parenting and cognitive schemas in a group of male adult offenders. Front Psychol, 7, 302. https://doi.org/10.3389/fpsyg.2016.00302

Peter, S. (2017). Innovation in Education: What Works, what doesn't, and what to do about it?. Journal of Research in Innovative Teaching and Learning, 10(1), 4-33.

Pinquart, M. (2017). Associations of parenting dimensions and styles with externalizing problems of children and adolescents: An updated meta-analysis. Developmental Psychology, 53(5), 932-973. https://doi.org/10.1037/dev0000295

Pinquart, M., \& Kauser, R. (2018). Do the associations of parenting styles with behavior problems and academic achievement vary by culture? Results from a meta-analysis. Culture Divers Ethnic Minor Psychol, 23(1), 75-100. https://doi.org/10.1037/cdp0000149

Purification, C., \& Alicia, A-G. (2018). Parenting Styles, Academic Achievement and the Influence of Culture. Pyschol Psychother Res Stud, 1(4).

Samiullah, S. (2016). Influence of Parenting Style on Children's Behavior. Journal of Education and Educational Development, 3(2), 222-249. https://doi.org/10.22555/joeed.v3i2.1036

Schonert-Reich, \& Kimberly, A. (2017). Social and Emotional Learning and Teachers. The Future of Children, 27(1), 137-155.

Thoma, P., Norra, C., Juckel, G., Suchan, B., \& Bellebaum, C. (2015). Performance Monitoring and empathy during active and observational learning in patients with major depression. Biology Psychology, 109, 222-231. https://doi.org/10.1016/j.biopsycho.2015.06.002

Toombs, E., Unruh, A., \& McGrath, P. (2018). Evaluating the Parent-Adolescent Communication Toolkit: Usability, and Preliminary Content Effectiveness of an Online Intervention. Nurs Open, 5(1), 29-36. https://doi.org/10.1002/nop2.107

Vygotsky, L. S. (2005). Psihologia razvitija Teloveka [Psychology of human development]. Moskva: Smõsl.

Yi-Chan, T., \& Mei-Ju, C. (2013). Interrelationships between Parenting Styles and Teachers Involvement: From Children's Emotion Regulation Competence Perspective. Journal of Applied Sciences, 13, 1066-1072. 